\title{
Do They Really Know What They Need? Prototypes and Different Research Methods as a Means of Testing Students'Feedback - A Case-Study
}

\author{
Ninon Franziska Frank \& Jarmo Schrader \\ University Library of Hildesheim, Hildesheim, Germany
}

This is an Accepted Manuscript of an article published by Taylor \& Francis in New Review of Academic Librarianship on 28/02/2021, available online: https://doi.org/10.1080/13614533.2020.1810080.

To cite this article: Ninon Franziska Frank \& Jarmo Schrader (2020) Do They Really Know What They Need? Prototypes and Different Research Methods as a Means of Testing Students'Feedback - A CaseStudy, New Review of Academic Librarianship, 26:2-4, 433-444, DOI: 10.1080/13614533.2020.1810080

\section{ABSTRACT}

Adopting a demand-oriented perspective helps librarians to understand their users better. Involving them in ongoing changes has the potential to have a lasting positive effect on the satisfaction of existing users and the recruitment of new ones. Three case-studies, which involved creating new learning spaces at the University Library of Hildesheim lead to the understanding that librarians need to employ attitudinal and behavioural research techniques to reach that goal because users - as it turns out - often do not really know what they need until they get a chance to try it.

\section{Introduction}

The digital change in libraries - from the 'book-centered paradigm' (Bennett, 2009, p. 184) to 'digital libraries' (Bennett, 2006, p. 3) - has led to a change of focus. Increasingly it is not the literature or databases, which draw students to the library (see Poth \& Fricke, 2019, p. 26) but the opportunity to use this special and quiet space to achieve academic success by learning for their exams, preparing their presentations, and writing their papers (Cohen, 2019).

As Scott Bennett puts it: "The "ultimate question of life" regarding academic library space is about learning and not about information consumption, because in truth the latter is only a means to the former' (Bennett, 2006, p. 7). Instead of concentrating on services, librarians are supposed to see the library as 'a learning enterprise' and see themselves as 'educators' (Bennett, 2009, p. 194).

So how do students learn? Not only do they need the right material, they also need the right social and physical environment, which is - to complicate things further - different for every student. Students know that learning regularly happens in a community, and the ability to manipulate the social dimension of learning is essential to their success in focussing on their studies, in disciplining themselves for learning. Successful design requires that we listen attentively and thoughtfully to what students tell us about the behaviours they successfully use themselves for study (Bennett, 2007, p. 18).

By observing the users, by doing (guerrilla) interviews and by mapping their ways throughout the library, librarians use an 'ethnographic agenda' (Lanclos, 2016) to gain insight into their behaviour in order to understand their needs (better). When (re)designing library spaces to adapt them to the needs of users, it should be obvious 
that these users should be involved in the process and their feedback sought (see Schaab \& Horstmann, 2016, p. 445). Given that the library as a study space has such a profound impact on students' academic life - it should surely be the librarians' job to support them in their pursuit of academic success by providing them with just the kind of environment they need.

Unfortunately, finding out what users need proves to 'be deceptively difficult' (Emary, 2016, p. 68). The ethnographic approach as described by Bryony Ramsden (2016) not only provides various methods to understand users and their needs better, it also reveals misconceptions about feedback.

The first step to expand our design toolkit was to organise a workshop on user experience research. Guerrilla interviews were instigated as an attitudinal research method (Schmidt \& Etches, 2014, p. 14) and open questions were asked about the library.

Initial analysis of data gathered from the interviews helped uncover a number of recurring topics, prompting a redesign of study spaces based on user feedback. Three case studies from the ongoing improvement process are described; each involving changes to study spaces where more variety is the key to more user satisfaction.

The exercise proved to be more complex than anticipated because not every change was welcome. Some pushback had been expected, however, and so a safety net called prototyping (Heath, 2016, p. 62) was employed that allowed ideas to be tried out before significant expenditure was committed to construction and furniture. This approach involved creating a simple, low-cost mock-up version of the new design, gathering user feedback and modifying the design as appropriate before implementing the final version. The value of this incremental approach to change was justified as it provided evidence as to which ideas worked in practice - not every great idea turns out to be the right solution for a problem.

User feedback proved to be an essential tool to find the right solution. Through experiments with, and analysis of, different modes of feedback and user interaction, the conclusion was that at least two different forms of interaction should be employed whenever possible in order to retrieve useful data.

Although it would appear that growing up as digital natives has substantially changed students' needs concerning the library as a learning environment, it is not at all obvious whether their preferred way of giving feedback has also changed. A comparison of postings via Facebook with 'classic' written or oral forms provided interesting insights into the most successful ways of acquiring feedback. As it turns out, the success lies in the combination of different forms to find out what users really need without consciously knowing it.

\section{Theoretical approaches}

The University of Hildesheim, which emerged from the Teacher's Training University of Lower Saxony, was founded in 1946. In 2003 it changed its status and has been a foundation under public law ever since. Despite growing numbers of enrolled students 
$(8,765$ in the winter semester of $2019 / 20)$, the university belongs to the smaller to medium sized universities in Germany. The university's library is part of the unit for consultation and services. It aspires to live the 'culture of enabling' which Wolfgang-Uwe Friedrich, the president of the university, proposed as key concept in his New Year's address in 20191. In embarking on an ongoing process of improving the library, it was important to make sure that as study spaces were redesigned, the appropriate tools were at hand to measure success. By involving users in different ways and in different settings, it was hoped to learn more about how they use the spaces provided.

The decision was taken not to conduct classical surveys with multiple choice questions or rating scale questions as they remove the need for real interactions with users and their experience in the library. Andy Priestner and Matt Borg summarise the flaws of traditional surveys by stating, 'that they are largely completed by pro-library users and that self-reporting is commonly understood to be unreliable. Our users have been telling us what they think we want to hear [ ... ]' (Priestner and Borg, 2016, pp. 1-2).

Instead, users' opinions were sought in three different ways: planned changes were posted on the library's Facebook page with a request for feedback; paper questionnaires with one question and large blank spaces to respond openly were laid out in the area where the changes happened. A flipchart was put up with either an open question or the possibility to vote on two options. While being similar to a questionnaire, the flipchart is more open and visible, literally serving as a standing reminder of the opportunity to interact with us.

All three methods have their benefits and drawbacks, as is discussed in detail in the following case studies, relating to reach, distance versus proximity, and reaction time.

In addition to users' responses, quantitative data as a more objective counterpart to the subjective feedback from our users was collected. Taking a dual approach helped both to find out more about user behaviour and also provided useful insight into the use of different feedback techniques.

\section{Case studies}

Three case studies are presented below to illustrate how library spaces were remodelled involving students' feedback. All three cases adopted the same approach. Firstly, a usage baseline for the area of interest was established with quantitative information being collected about how, and how often, users frequented the space during a period of two to three weeks.

Secondly, the same space was modified while continuing to collect quantitative data during a similar period. As a behavioural research method, this demonstrated where users actually preferred to sit (Schmidt \& Etches, 2014, p. 27). In each of the three cases, there was a clear difference between the baseline and the modified condition.

\footnotetext{
${ }^{1}$ https://www.uni-hildesheim.de/media/presse/20190109_Rede_des_Praesidenten_Professor_Wolfgang-Uwe_Friedrich_ Neujahrsempfang_der_Uni_Hildesheim.pdf; last visit on 07.08.2020
} 
Thirdly, in order to find out how users felt about the modifications, they were asked for feedback in print and via social media (Facebook) as described above.

The Facebook account of the University Library of Hildesheim had been started as a part of an apprentice's project. Since 2015, a team, and later on, a person takes charge of content on a regular basis. The account had approximately 980 followers during the case studies shown in this article. The numbers have increased since then. Statistically around 10 percent of the (former) students seem to follow the account on Facebook.

By contrasting quantitative data from observations with the feedback gained on paper and via Facebook - insight into users' needs was achieved, but also signs of an attitudebehaviour gap were revealed.

Reading room: more places vs more space

The reading room was constructed as a room separate from the main reading area. It is a long rectangular room, measuring $10.5 \mathrm{~m} 5.5 \mathrm{~m}$, with windows on all four walls: the front and right side open to the university campus, the left side faces the main reading area while on the fourth side is the entrance door (Figure 1). As a high intensity space without distractions it should enable students to work quietly and undisturbed. It originally held 26 places with single desks, each measuring $10060 \mathrm{~cm}$. They were arranged in a traditional classroom layout in rows of four, all facing the front window. Due to the limited size of the room, the tables stood relatively close to each other.

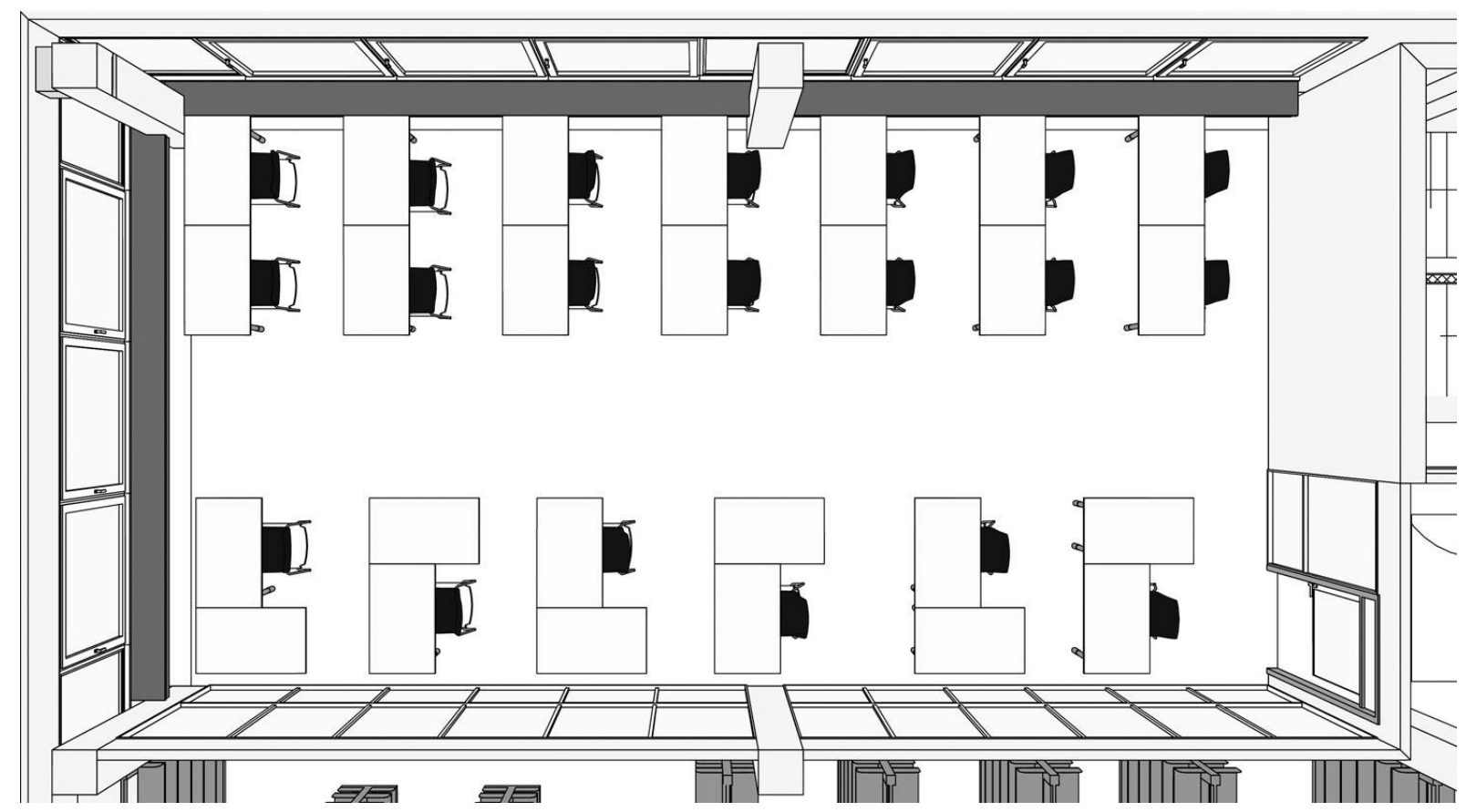

Figure 1 Reading room showing original table-layout on the top and modified layout on the bottom.

It was obvious from casual observation that the reading room was not used very much. In order to obtain more reliable data, library staff started to keep track systematically of where users chose to sit. For three weeks, the information desk staff would visit the room at intervals of two hours from ten a.m. until six p.m. and recorded which places were occupied. 
The survey showed that half of the 26 places were never or rarely used during the recording period. Interestingly, the rarely used desks were the ones in the middle of the room whereas the seats next to the windows and walls were occupied more often with window seats looking out over the campus being the most popular. Observations also showed that students used the windowsills as an additional storage surface.

As a first response to the survey, half the tables along the less popular wall facing the main reading area were rearranged. Two desks were placed at 90-degree angle to each other, creating a larger L-shaped desk space for one person. This resulted in a reduction of workplaces from 26 to 20.

A subsequent survey showed an interesting change in user behaviour: before rearranging the desks as above, six of the twelve places were never or rarely used. Afterwards, all six desks were used more frequently than before. The average occupation increased from 12 percent to 35 percent. In addition to collecting statistical evidence, information on users' preferences was gathered in print and via Facebook through the following question: Is it better to have more space for fewer users or less space for more users? Users could vote for one of the two options and comment as well. In the Facebook survey, 123 users, which are more than 12 percent of the followers, took part with a majority of 54 percent preferring more places to more space. There were no comments.

The advantage of using Facebook is an overview called 'performance for your post' which shows, for example, how many people were reached, how many clicks and likes the post received, and how often it was shared. According to this metric, the survey reached 565 people of whom 22 percent decided to interact by answering.

The printed version of the survey available in the reading room had fewer participants. 38 answers were received with a very different result: On site, a majority of 66 percent (25 respondents) preferred more space to more places with 29 percent (11 respondents) choosing the opposite. The remaining two respondents preferred a mixture of both seating configurations, which means that they preferred the first step of the rearrangement - an option that was only available in the paper survey as they added this to the initial one.

How can the different results from the online and on-site surveys be explained? A possible explanation could be that having more places available in the library seems attractive from a distance while actually sitting and working at these desks and experiencing their limitations, offers a significantly different perspective.

The evidence from the usage data supports the view of the users on site. Therefore, the decision was taken to reduce the number of working places a second time by mirroring the desk set-up for the campus-facing wall. During a similar period as before, statistical data was again collected and the opportunity to give feedback on the recent changes was offered. The second survey was not available on Facebook.

The feedback from the second survey was similar to the first. Thirty people chose to answer. The majority again preferred the L-shaped desks, because they provided more place, and also noted in comments that they enjoyed the silence that comes with a 
smaller number of users and single desks. They also stated that the reading room was the only really quiet space in the library where distractions were minimal.

The statistical data also showed an increase in the use of the campus-facing area. Before the rearrangement of the desks, the occupancy rate was 15 percent, increasing to 36 percent after the change.

These numbers also show that by reducing the quantity of desks the quality of the remaining working places was increased. The average number of users in the room at one time was also increased: from 3.7 users in the original space configuration to 4.4 after the first rearrangement and 5.3 after the second.

The project had the additional benefit of providing insight as to how users react to different methods of giving feedback. Although a wider audience and more participants were reached using Facebook, the feedback received on site was more realistic as spatial proximity is a key component in getting answers that are close to a lived truth.

Theoretically, users like the idea of more seats. Nevertheless, do they really know what they need for an ideal working atmosphere? When answering online they do not take the disadvantages of overcrowding, noise and proximity to other users into account. However, the reality of working in a limited space with other users in close proximity leads to different answers.

It seems important, therefore, to make sure that users have had a chance to actually experience a given type of environment before gathering their feedback. Consequently, social media can be seen as a good way of disseminating information and interacting with users, but its reliability in giving insights into users' actual needs is limited.

\section{Movable dividers: separating spaces and separated feedback}

The guerrilla interviews conducted during the user experience workshop revealed that users wanted spaces for focussed and private study. While providing study carrels might have been the best way to satisfy this demand, space and budget constraints compelled the library staff to look for a different approach.

Due to the transition from print journals to e-journals, space beside the windows was freed up. New working spaces were created where users could work together quietly in four groups of six tables. Since this area is located next to one of the main pathways through the building, the plan was to use movable dividers to maintain a feeling of privacy while studying.

Since movable dividers are surprisingly expensive, the decision was taken to simulate the situation prior to purchase. Large movable pin boards were borrowed from the university's media rental at no cost and, although much less attractive than the planned ones, served the purpose. 


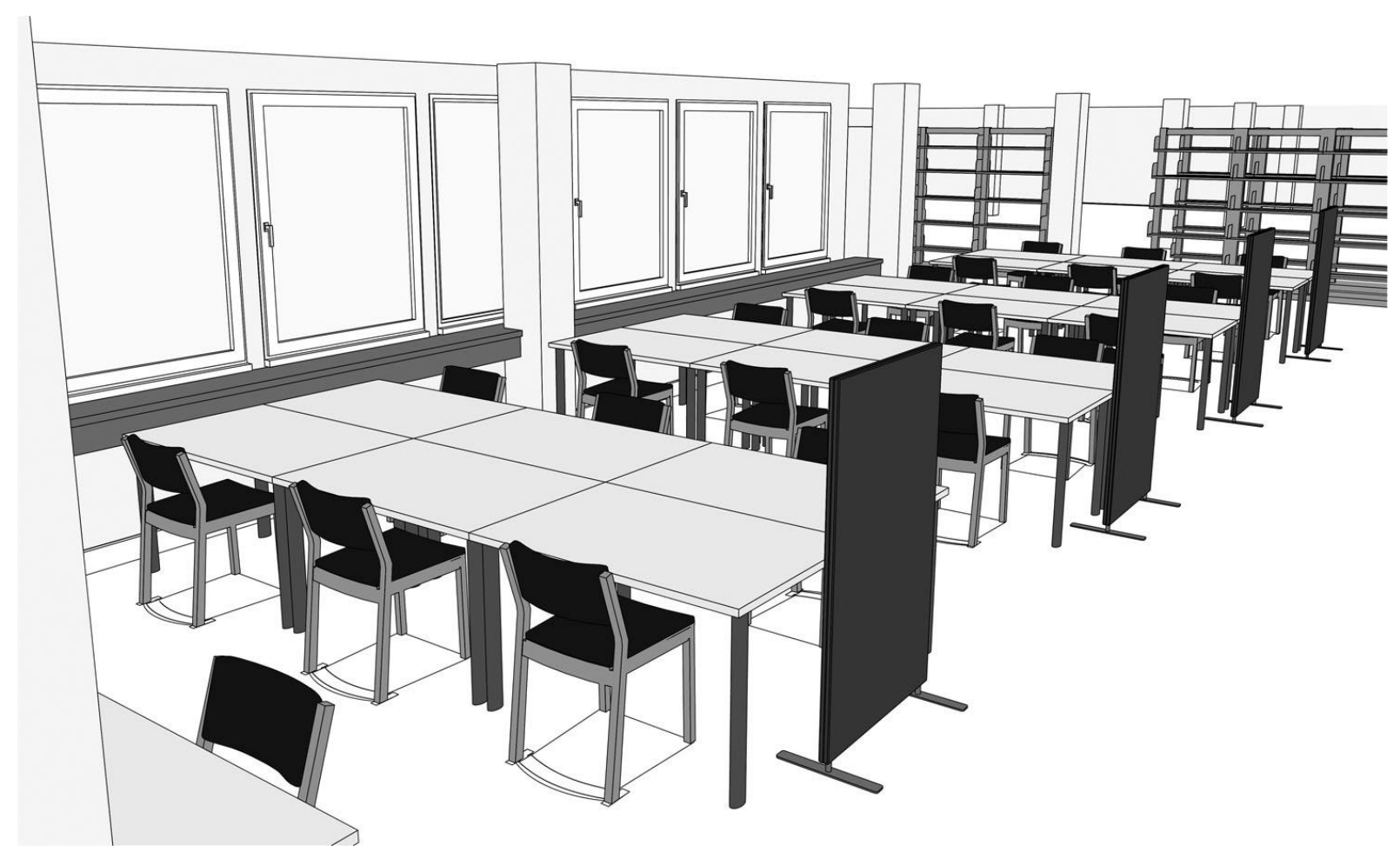

Figure 2 3D-model of proposed redesign for working spaces with movable dividers.

Although the movable dividers looked good in a 3 D mock-up created before setting up the new area (Figure 2), it soon became apparent that they were not a success. The feedback gathered on site was almost exclusively negative. Twenty users voted on this issue and a majority of sixteen did not like them. The comments s ranged from 'They bother me!' to 'I don't see any purpose in them?'

595 users were reached via Facebook representing a small increase compared to the survey on the reading room. It had eight likes. Only three users commented on the post: one with a suggestion for an alternative, one on an unrelated subject, and one in favour of the dividers.

This 'failed' experiment thus provided first hand evidence that it is a good idea to try things out with a prototype first and get feedback before committing serious resources and money. By prototyping before buying, not only was money saved, but also adverse user reaction was avoided in the longer term.

The experiment also confirmed the observation about the usefulness of on-site feedback. While the post on Facebook helped to inform our users, very little insight into their habits and preferences was gained. The on-site feedback, however, was very informative and helpful.

\section{Reading lounge: creating an eating-zone}

The third case study produced surprises in that the final outcome took an unexpected turn but lessons were learned about the users and the ways they use the library.

One of the suggestions we received from students during the guerrilla interviews was to redesign the 'reading lounge' ('Leselounge' in German). This spacious room is located off 
the main reading area. It was intended as a relaxation zone and was furnished with several armchairs, easy chairs, low coffee tables, and a red sofa. Daily newspapers were on display as well as bookshelves with publications by university members.

Years of intense use had taken their toll on the furniture, which looked old, shabby and worn out. Users complained that the reading lounge was too full and too dull, and that the furniture needed replacing.

One advantage of the reading lounge is that it is an enclosed space, which opened up the possibility of addressing another suggestion from our guerrilla interviews, which was to rethink and relax our library's food policy. A high number of interviewees said that they would like to bring snacks into the library. As (academic) libraries have a long history of strict no food and no drink (apart from bottled water) policies (Lyons, 2000), this is a controversial issue.

Users do not want to leave their study places to eat and drink. Libraries ${ }^{2}$, on the other side, argue that their books, floors and furniture need protection from possible spills, that pests could be attracted by leftover food (Deng et al., 2019, p. 825; Shill \& Tonner, 2003, p. 457) and that other users should not be disturbed by smells. ${ }^{3}$

Lyons's study from 2000 offers a different view on this discussion, however. Libraries with a strict no food and no drink policy face opposition when considering lifting the ban. Libraries that gradually eased their restrictions on food and drink however, reported only a few complaints (Lyons, 2000, p. 342).

The decision at University of Hildesheim, therefore, was to rethink the library's food policy. Before redesigning the room, a new communication strategy for food policy, was developed. It focussed on pictograms and a short list of do's and don'ts. This poster was placed throughout the room and, in addition, was shown on the library's information screen, website and Facebook page

For the redesign of the room, tables and chairs different from those in the rest of the library were used to underline that this is a different area where other rules apply. Almost all the comfortable furniture, including the red sofa were moved to other parts of the library to be part of yet another experiment. In addition, cleaning materials and bins were supplied and a flipchart was provided for further feedback.

Based on the information from the guerrilla interviews, staff expected that this change would have repercussions. However, no problems arose, users were happy with the new food and drink policy and instead the surprising reaction to the redesign of the reading lounge was the disappearance of the red sofa!

Our Facebook post, which showed photos of the new 'Leselounge' and explained the new rules, reached 3751 people - just because the beloved red sofa was not there anymore which means that this message generated six times the response of other posts on

\footnotetext{
${ }^{2}$ See the following statement of the University of Kassel as an example for almost all academic libraries, at least in Germany: https://blog.ub.uni-kassel.de/blog/2017/05/17/essen-trinken-in-der-bibliothek/; last visit on 13.12.2019. Public libraries tend to be more open to this issue

${ }^{3}$ See this discussion on reddit.com: https://www.reddit.com/r/Libraries/comments/3v7s4v/should_food_and_ drinks_be_allowed_in_libraries/; last visit on 13.12.2019.
} 
previous changes. Numerous users commented on the flipchart about missing the sofa (for a nap) and demanded its return.

In response, further feedback was sought using the flipchart asking users if they wanted more sofas or more tables. While the second option remained at a low level, the votes (and drawings of sad faces) for more sofas increased every day quickly reaching 35.

The sofa was returned to great applause from users - and a sofa-readinglounge-reunion day is to be held. On a more serious note, the need to provide a space to relax - even sleep - was identified.

The redesign project also illustrated how the outcome of changes is not always predictable. However, by giving users ways to interact with library staff, information about their needs, their user experience and, finally yet importantly, about their preferred way of giving feedback is brought to the surface.

\section{Discussion and outlook}

The question posed at the start of the space projects was whether users actually know what they need. Evidence gathered suggests they often do not know what they need, because having an idea about something in the abstract and actually experiencing it, are quite different things.

As the case studies at Hildesheim University Library show, many lessons were learnt. Focussing on statistics and numbers is a helpful step but it shows only a (small) part of the whole picture. When users complain about the lack of study spaces, simply increasing the number of chairs and tables can be an option, but it might not be the best one. Hoping to increase user numbers just by increasing the numbers of seats, is a solution that is shared by Shill and Tonner (2003, p. 450). As the first case study concerning the reading room proves, more places is not the solution. The prototype testing - especially in the reading room - clearly shows that the quality of the available study spaces strongly influences where users choose to sit and work. A simple expansion, therefore, will increase occupancy only during peak times where user expectations are lowered due to the limitation of seats.

User experience-based processes can take longer than expected. Prototyping an idea can mean that it needs several rounds of adjusting and testing to come up with a final result. This may be difficult but working in this way will produce better results.

In addition, sometimes an idea looks good on paper but fails completely in the real world, which was the case with the movable dividers. What can seem to be a failure, however, can also be a learning opportunity. Testing ideas using prototypes, means financial investment is minimal and the interactions with users increases mutual understanding and gives surprising insights as to why users do things the way they do. Thus, involving users in the process by asking them directly and reaching out to them for feedback on various stages of prototypes, helps to find optimal solutions.

Surprisingly, the generation of digital natives responded more frequently to 'old', written forms of feedback instead of 'new', digital forms. As the University Library does 
not have other social media accounts (like Instagram or Twitter), a comparison and, with that, an overall statement is not possible. ${ }^{4}$

The reach of Facebook posts is wider by far but the lack of active feedback gave little insight into users' experiences. As a result, the library will continue to use its social media account to spread the word about ongoing changes in order, it is hoped, to raise awareness about them.

Flipcharts and questionnaires, on the other hand, provided deep and valuable insights into users' views. Astonishingly, users responded better to these seemingly outdated forms of interaction than to the ever-present social media. Presumably, being on site and having these experiences as users while getting the chance to comment directly in an easy, almost anonymous way, resulted in a willingness to be involved and led to a deeper understanding.

However, we need to take a step back and turn the question on ourselves as librarians: do we as librarians know (better) what our users need? The answer is the same: no. Our profession does not provide us with a crystal ball that can reveal the deepest needs and desires of our users. While our professional knowledge is an important prerequisite for creating a successful learning environment, we have to augment it with additional information about user behaviour and user needs. Therefore, we need to listen and continue the dialogue with our users employing the range of feedback methods explored in the small projects described above.

\section{References}

Bennett, S. (2006). The choice for learning. The Journal of Academic Librarianship, 32 (1), 3-13. doi:10.1016/j.acalib.2005.10.013

Bennett, S. (2007). First questions for designing higher education learning spaces. The Journal of Academic Librarianship, 33 (1), 14-26. doi:10.1016/j.acalib.2006.08.015.

Bennett, S. (2009). Libraries and learning: A history of paradigm change. Portal: Libraries and the Academy, 9 (2), 181-197. doi:10.1353/pla.0.0049.

Brow, J. S. (2002). Learning in the digital age. In M. Devlin, R. Larson, \& J. Meyerson (Eds.), The Internet and the University: Forum 2001 (pp. 65-86). Boulder, CO: EDUCAUSE and the Forum for the Future of Higher Education.

Cohen, D. (2019, May 26). The Books of College Libraries are turning into Wallpaper. Washington D. C.: Atlantic Media. https://www.theatlantic.com/ideas/archive/2019/05/ college-students-arent-checkingout-books/590305/.

Deng, Q., Allard, B., Lo, P., Chiu, D. K. W., See-To, E. W. K., \& Bao, A. Z. R. (2019). The role of the library cafe as a learning space: A comparative analysis of three universities. Journal of Librarianship and Information Science, 51 (3), 823-842. doi:10.1177/ 0961000617742469

Emary, L. (2016). The why, what and how of using ethnography for designing user experience in libraries (and a few pitfalls to avoid). In A. Priestner \& M. Borg (Eds.), User Experience in Libraries. Applying Ethnography and Human-centred design (pp. 68-83). New York, NY: Routledge.

\footnotetext{
${ }^{4}$ Another interesting case-study would be the comparison of different social-media channels which takes into account that Instagram is used more frequently by young adults at the age of 18 to 24 than Facebook. See: Haak (2019).
} 
Haak, S. (2019, 12 June). Instagram löst Facebook als wichtigste Nachrichtenquelle ab. Grunderszene. $€$ https://www.gruenderszene.de/media/instagram-facebook-nachrichten.

Heath, P.-J. (2016). Applying human-centred design to the library experience. In A. Priestner \& M. Borg (Eds.), User Experience in Libraries. Applying Ethnography and Human-centred design (pp. 49-67). New York, NY: Routledge.

Lanclos, D. M. (2016). Embracing ab ethnographic agenda. Context, collaboration, and complexity. In A. Priestner \& M. Borg (Eds.), User Experience in Libraries. Applying Ethnography and Human-centred design (pp. 21-37). New York, NY: Routledge.

Lyons, D. B. (2000). No food, no drink - no more? A study of food and drink policies and practices in public libraries. Public Libraries Chicago, Illinois, 39 (6), 338-347.

Poth, D., \& Fricke, F.-S. (2019). Gemeinsam die Zukunft gestalten. Partizipation im Strategieprozess der Benutzungsabteilung an der SUB Göttingen. 0-Bib. Das Offene Bibliotheksjournal, 6 (4), 25-38. doi:10.5282/o-bib/2019H4S25-38.

Ramsden, B. (2016). Using ethnographic methods to study library use. In A. Priestner \& M. Borg (Eds.), User experience in libraries. Applying ethnography and human-centred design (pp. 9-20). New York, NY: Routledge.

Schaab, R., \& Horstmann, W. (2016). Bis morgen in der Bibliothek!' - Entwicklungen fur € Lernorte an der SUB Gottingen. € Bibliothek - Forschung Und Praxis, 40 (3), 444-451.

Schmidt, A., \& Etches, A. (2014). Useful, Usable, Desirable. Applying User Experience Design to your Library. Chicago, IL: American Library Association.

Shill, H. B., \& Tonner, S. (2003). Creating a Better Place: Physical Improvements in Academic Libraries, 1995-2002. College \& Research Libraries, 64(6), 431-466. November 2003, doi:10.5860/crl.64.6.431. 